\title{
ROLE OF PLANT SECONDARY METABOLITES IN COMBATING PEST INDUCED STRESS IN BRINJAL (SOLANUM MELONGENA L.)
}

\author{
Pratik TALUKDER $\mathbb{D}^{*}$, Debankita DUTTA, Elija GHOSH, Indrani BOSE, \\ Sourish BHATTACHARJEE
}

Department of Biotechnology, University of Engineering and Management, Kolkata, India

Received 31 October 2020; accepted 28 December 2020

\author{
Highlights \\ Impact of plant secondary metabolites in mitigating biotic stress. \\ Role of polyphenols in pest control. \\ Alternate strategy to combat pest. \\ Plant secondary metabolites as biopesticide.
}

\begin{abstract}
Brinjal or eggplant (Solanum melongena L.) is known as a vegetable of diet because it contains high moisture and low calorific value. It is also a good source of antioxidants and phytonutrients. Brinjal is widely grown in the South and South-East Asian countries and is the second most important vegetable in India. It belongs to the Solanaceae family. Shoot and fruit borer (Leucinodes orbonalis) pest of brinjal is the most widespread one and it has the ability to affect any of the developmental stages of brinjal. Plants and their insect herbivores have had a long and intimate evolutionary association that has resulted in many complex interactions mediated by specialized plant metabolites like phenolics, alkaloids, terpenoids, cyanogenic glycosides etc. Frequent and excessive use of insecticides has become a common practice now which only increases the probability of resistance development and resurgence of pest. Hence to develop an effective approach to combat this pest understanding of its feeding mechanism and chemistry of its interaction with the fruit is necessary. The importance of the secondary metabolites in the field of chemical biology and in pest management is discussed in this study.
\end{abstract}

Keywords: secondary metabolites, chlorogenic acid, hydroxycinnamoyl-CoA quinate hydroxycinnamoyl transferase (HQT), Solanum melongena L., brinjal shoot and fruit borer (Leucinodes orbonalis L.).

\section{Introduction}

Brinjal (Solanum melongena) is one of the most important vegetables (Yann, 1972). There are several impediments to the cultivation of brinjal. A huge loss is incurred due to pest infestation. There are several species of insect pests which are found to attack brinjal and it is proven in several studies (Alpuerto, 1994). Brinjal shoot and fruit borer, leaf hopper, aphid and brinjal stem borer are few common pest of brinjal (Nasif \& Siddiquee, 2020). Out of these numerous pests, the most dangerous is the Shoot and Fruit Borer (SFB), Leucinodes orbonalis which is considered to be a limiting factor in brinjal cultivation (Maureal et al., 1982). Production of brinjal suffers a colossal loss due to the infestation of the shoot and fruit borer, a lepidopteran insect. SFB larvae enter the internal tissue of the plant and become inaccessible to the external environment by sealing their entry points with their silk and excreta. In fruit, they bore deep in the mesocarp and exit only at the time of pupation. Therefore, the contact insecticides have not been effective against it. In spite of this, frequent and excessive use of insecticides has become a common practice and unfortunately increasing day by day, which only increases the probability of resistance development and resurgence. Thus to design an effective strategy against this pest, understanding of its feeding mechanism and chemistry of its interaction with the fruit is of utmost importance. However, studies on these aspects are scarce. One of the rare studies on the chemistry of brinjal-SFB interaction suggests that brinjal phenolics may impart resistance against SFB (Dar et al., 2017). This is highly interesting, especially because while boring in mesocarp SFB

*Corresponding author. E-mail: pratiktalukder@gmail.com 
larvae ingest large amounts of phenolics and their skin also remains in constant touch with phenolics, as they remain buried in this phenolic-rich tissue. Phenolic-rich plant tissues are known to turn brown upon damage because of the oxidation of phenolics due to the exposure to the environmental oxygen. The SFB excreta also rapidly browns upon deposition indicating that oxidation occurs only upon the excretion of phenolics and they are oxidation-protected in the digestive tract. Another lepidopteran generalist Spodoptera exigua excretes the ingested phenolics unchanged; it suggests the presence of oxidation-prevention mechanism in lepidopterans. However, the biochemical and molecular basis of this mechanism is not clearly known. Preliminary field observations reveal that when larvae present near the plant surface are attacked by natural enemies like predators and parasitoids, they aggressively defecate towards these enemies, most probably to deter them.

The initial step for pest management and control is usage of chemicals. As brinjal is a staple food and consumed in its original form, usage of synthetic insecticides is hazardous to human health. Due to overuse and misuse of these chemical insecticides, natural balance has been disturbed leading to enormous problems such as environmental contamination, resistance, bioaccumulation and biomagnification of toxic residues, resurgence, destruction of natural enemies (Jena et al., 2006). Use of pesticides often comes as a threat to natural enemies also. In this case the victim are Chrysoperla sp. (Neuroptera), the predator and Trathala flavoorbitals (Hymenoptera), the parasitoid and other harmless insects or the insects which are not the target. So, an alternate and comparatively safer method is urgently needed. The most important and effective way to manage an insect pest is the recommendation of disease control programmes in the agricultural systems (Anwar et al., 2015). The strategy of host plant resistance against the shoot fruit borer serves as an excellent component of Integrated Pest Management (IPM). One of the basic components of IPM is development of resistant and tolerant cultivars because it reduces the use of insecticides. Hence, several investigations are being carried out regarding the usage of more eco friendly organic bio-pesticides than the synthetic ones and response of pests are being recorded to assess the effectiveness of the biopesticides.

\section{Description of brinjal (Solanum melongena L.)}

Solanum melongena $\mathrm{L}$. is commonly known as eggplant or brinjal or aubergine which belongs to the kingdom Plantae, division Magnoliophyta, class Magnoliopsida, order Solanales and it is the member of the potato family Solanaceae. The corresponding genus name is Solanum with species name melongena.

It is one of the most important, common, popular and economically important vegetables grown throughout the world. Brinjal is commonly cultivated in almost all states of India in about 5.10 lakh hectares of land and the average annual production is 88 lakh tonnes (Singhal, 2003). It has high nutritional value. Few studies also suggest that some of the secondary metabolites of brinjal have anti carcinogenic effect (Gürbüz et al., 2018). It also acts as dietary fiber. Natural antioxidants such as polyphenolic compounds are present in high content in brinjal, hence it is capable of quenching high amount of reactive oxygen and nitrogen species (Cao et al., 1996). Among the major crops of Solanaceae family brinjal is the fifth most important crop from the point of view of economic value (Taher et al., 2017). Solanum melongena L. is a non woody or soft wooded herb; mostly branched and about 1-2 metres tall. A long taproot system extends deep into the soil.

\subsection{Stems and leaves}

The stems and leaves are densely covered with sparse or dense pubescent stellate hairs and prickles which are also present on calyx but fewer in number. Glandular hairs are also present, but not that noticeable. It exhibits alternate phyllotaxy. Each leaves has a petiole of about 6 to $10 \mathrm{~cm}$ long. Average length of the leaves is from 3 to $25 \mathrm{~cm}$ and average width varies from 2 to $15 \mathrm{~cm}$. Leaves have hairy margins. Leaves are ovate or oblong in shape, entire or with 5 to 9 shallow sinuate lobes, lobes and sinuses rounded, with unequal bases. The lower surface of the leaves is pale green as compared to the upper surface.

\subsection{Inflorescence}

Flower is considered as the modified shoot. The shoot bears flowers only when the apical shoot meristem changes to floral meristem. The flowers appearing on the shoot are either in singular arrangement or in clustered manner.

\subsection{Flowers}

The hermaphrodite flowers are solitary which are supported by a pedicel of 1.5 to $3 \mathrm{~cm}$ long; it is relatively stout and soon deflexed. These hermaphrodite flowers are about 3 to $4 \mathrm{~cm}$ in diameter and are mostly violet and very rarely white. The anthers present are oblong, erect and stout and about 5 to $7 \mathrm{~mm}$ long; and supported by short, thick filaments of about 3 to $4 \mathrm{~mm}$ long and have openings at their tips. The ovary is positioned above the sepals, petals and stamens hence superior in nature.

\subsection{Fruits}

The fruit is a depressed globose to oblong or ovoid fleshy berry. Fruits are about 2 to $35 \mathrm{~cm}$ long and 2 to $20 \mathrm{~cm}$ broad. Generally, the fruit is smooth and glossy with multiple seeds. The seeds are kidney shaped or lentil shaped, flattened and pale brown in colour. It gives fruits throughout the year and it is perennial. The peel of deep blue or purple colored varieties of brinjal has significant amounts of phenolic flavonoid phytochemicals which helps to fight against cancer, aging, and neurological diseases (Stommel \& Whitaker, 2003). 


\section{Importance of major phenolics}

Class phenolics constitutes of phenolic acids, flavonoids, lignans, stilbenes and tannins, which is structurally diverse, ranging from monomeric phenolic acids to complex polymers like tannins (Vogt, 2010). Phenolics in fruits and vegetables represent the major class of antioxidant supplements in our diet (Dawidowicz \& Typek, 2015). There are many types of secondary metabolites. Some of them are- terpenoids and steroids, alkaloids, fatty acid-derived substances and polyketides, non-ribosomal polypeptides and enzyme co-factors.

Many natural antioxidants such as polyphenols are present in high amount in brinjal with chlorogenic acid (CGA) being the most abundant one (Clifford et al., 2003). Isomers of Chlorogenic acid - crypto chlorogenic acid (4-O-caffeoylquinic acid) and neochlorogenic acid (3-O-caffenoylquinic acid) are also present but in lesser amount (Corse et al., 1965). Besides the antioxidant activities CGA also have many activities such as the antiinflammatory, anti-mutagenic and anti-proliferative ones (Kan et al., 2014). CGA is regarded as one of the most important antioxidants in our diet (Naveed et al., 2018). Brinjal is known to be the chief vegetable source of CGA, which accounts for more than $75 \%$ of the total brinjal phenolics.

\section{Biosynthesis of CGA}

CGA is produced by the phenylpropanoid pathway. Caffeoyl CoA and quinic acid are the precursors of CGA formation (Barnes et al., 1950; Clifford, 1999). Hydroxycinnamoyl-CoA quinate hydroxycinnamoyl transferase (HQT) enzyme catalyzes this reaction. Two other biosynthetic routes have also been observed in some plant species but they are known to be minor (Kashyap et al., 2003) (Figure 1).

\section{Description of Leucinodes orbonalis (Brinjal Shoot Fruit Borer - SFB)}

The Leucinodes orbonalis is commonly known as Brinjal shoot fruit borer. It is an arthropod and belongs to class Insect, family Crambidae. It is mostly found in the tropical region of Asia and it is a minor pest in America. It is an internal feeder pest of brinjal. It is a monophagous pest which feeds only on brinjal. This regular pest affects both yield and quality of brinjal Studies documented that this larva damages the shoots up to $15 \%$ and fruits up to $23 \%$ (Alam, 1970).

\subsection{Larval stage}

Larvae grow to $2 \mathrm{~cm}$ in length with segmented legs, mandibles and the body is divided into three parts - head, thorax and abdomen. It moults 4 times and passes through 5 instars (Singla et al., 2018).

\subsection{Pupal stage}

It has greyish boat-shaped cocoon. The pupal period is about of 7 to 8 days.

\subsection{Adult stage}

The adult moth is of white in colour and covered with brown scales. The fore wings are creamy white with reinform large patches of light brown colour over it. The female moth is generally larger than the male with tuft of hair at the tip of the abdomen. In the case of an adult male the average length is $7.66 \mathrm{~mm}$ and average width is $17.66 \mathrm{~mm}$ across the wings. Whereas in case of female the average length is $10.50 \mathrm{~mm}$ and average width is about $19.00 \mathrm{~mm}$ across the wings (Singla et al., 2018). The fore and hind wings consist of marginal hairs and bears pinkish-brown spots. The adult $L$. Orbonalis female lays about 250 eggs within 2 - to 5 days.

\section{Reduction in quality and yield due to infestation with SFB}

This peat is capable of damaging brinjal throughout the harvesting period. Larva of Leucinodes orbonalis is an internal feeder. Hence it immediately boars the plant part next to it and goes inside; it seals the hole with its faecal matters (Alam, 1970). As a result, the affected twigs, flower and fruits dries up, gets withered and may drop off. The fruit might get disfigured also. Larval feeding results in wilting of the shoot. Presence of wilted shoots in a brinjal field is the sign of damage by this pest. This results in reduction in plant growth, which in turn, reduces quality

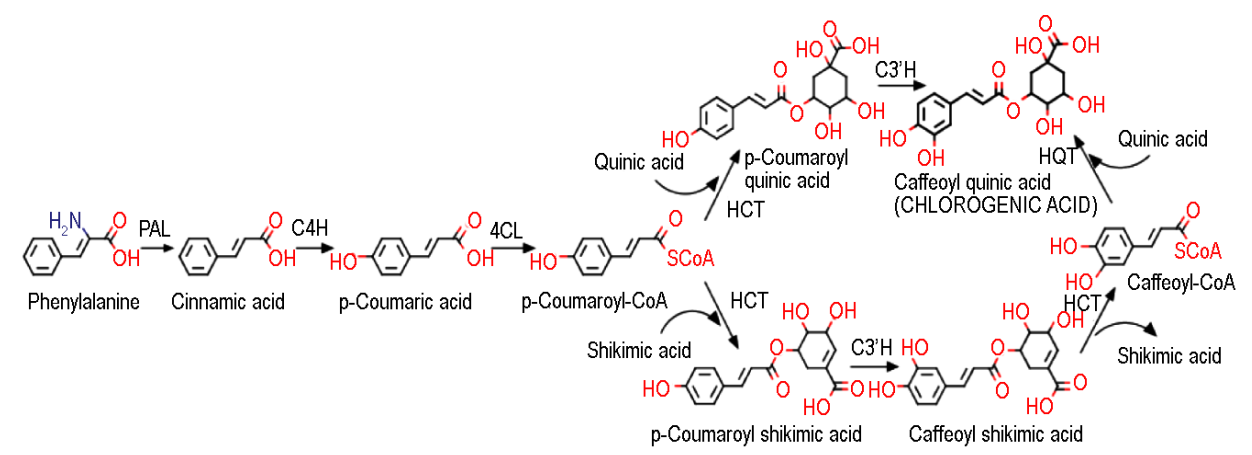

Figure 1. Pathway of CGA biosynthesis 
and yield. It also delays the fruit maturity. Due to larvae feeding flowers lose their fertility. The larvae feed on fruit tissue and hence directly reduce fruit quality and yield; on top of that they fill the feeding holes with their faecal matters and worsen the quality further and make the fruit unmarketable (Raina \& Yadav, 2018). The yield loss due to SFB attack varies according to seasons and locations. Studies also indicated that SFB attack also causes reduction in the nutritional value of the infested brinjals (Sharma, 2002). Hence the negative impact of SFB infestation is not only limited to the yield and marketability but also with nutritional quality of brinjal.

\section{Strategies involved to combat SFB infestation}

Natural enemy behavioural assays can be conducted to understand the ecological significance of CGA and its derivatives in the attacked SFB's frass. Chrysoperla sp. (Neuroptera) can be used as a predator and Trathalaflavo orbitals (Hymenoptera) can be used as a parasitoid. Both occur naturally in various brinjal-growing geoclimatic zones of India. Choice and no-choice assays for these natural enemies can be conducted to demonstrate the effect of CGA on them. For understanding the field-level impact, lowcost cages with controlled environment can be built and used as mesocosms in which, SFB larvae can feed in the fruits of CGA-deplete and control plants in the presence of the above-mentioned natural enemies. Prey or host locating and attack behaviours of natural enemies can be studied in these mesocosms for revealing the role of CGA in tritrophic interactions. If CGA is found to be a natural enemy deterrent, natural enemy-mediated integrated pest management can be prescribed for the protection of the low-CGA varieties. As the CGA incorporation within brinjal by genetic modification is a very complicated process so one can use CGA as a biopesticide. Increased chlorogenic acid level in crop plants may also provide protection against both herbivores and pathogens, which could increase crop yield.

\section{Conclusions}

Synthetic chemicals, insecticides and pesticides have a detrimental impact to the entire environment, hence use of organic insecticides or bio-pesticides are recommended. The present review concludes that the use of Integrated Pest Management system, along with the cultivation of resistant varieties can reduce the pressure of insecticides on the natural enemies, non-target and beneficial insects, pollinators, animal and human being that constitutes an ecological niche. This will defend the entire flora, fauna and the environment from toxic hazardous materials. Phenolics are the major secondary metabolites of brinjal, of them; Chlorogenic Acid (CGA) is the major phenolic compound and one of the most potent natural antioxidants. This review reports the importance of the plant secondary metabolites, especially chlorogenic acid in the field of chemical biology and in pest management.

\section{Acknowledgements}

The author sincerely acknowledges University of Engineering and Management.

\section{Conflict of interests}

The author declares that there is no conflict of interest.

\section{Authors' contributions}

All the authors contributed equally in preparing this manuscript.

\section{References}

Alam, M. Z. (1970). Insect pest of vegetables and their control in Bangladesh. Agriculture Information Service, Dacca, Bangladesh.

Alpuerto, A. B. (1994). Ecological studies and management of brinjal fruit and shoot borer, Leucinodes orbonalis Guenee. Indian Journal of Agricultural Sciences, 52(6), 391-395.

Anwar, S., Mari, J. M., Khanzada, M. A., \& Ullah, F. (2015). Efficacy of insecticides against infestation of brinjal fruit borer, Leucinodes orbonalis Guenee (Pyralidae: Lepidoptera) under field conditions. Journal of Entomology and Zoology Studies, 3(3), 292-295.

Barnes, H. M., Feldman, J. R., \& White, W. V. (1950). Isochlorogenic acid. Isolation from coffee and structure studies. Journal of the American Chemical Society, 72(9), 4178-4182. https://doi.org/10.1021/ja01165a095

Cao, G., Sofic, E., \& Prior, R. L. (1996). Antioxidant capacity of tea and common vegetables. Journal of Agricultural and Food Chemistry, 44(11), 3426-3431. https://doi.org/10.1021/jf9602535

Clifford, M. N. (1999). Chlorogenic acids and other cinnamates - nature, occurrence and dietary burden. Journal of the Science of Food and Agriculture, 79(3), 362-372.

https://doi.org/10.1002/(SICI)1097-0010(19990301) 79:3<362::AID-JSFA256>3.0.CO;2-D

Clifford, M. N., Johnston, K. L., Knigh, S., \& Kuhnert, N. (2003). Hierarchical scheme for LC-MS identification of chlorogenic acids. Journal of Agricultural and Food Chemistry, 51(10), 2900-2911. https://doi.org/10.1021/jf026187q

Corse, J., Lundin, R. E., \& Waiss, A. C. (1965). Identification of several components of isochlorogenic acid. Phytochemistry, $4(3), 527-529$. https://doi.org/10.1016/S0031-9422(00)86209-3

Dar, S. A., Rather, A. B., Wani, A. R., \& Ganie, M. A. (2017). Resistance against insect pests by plant phenolics and their derivative compounds. Chemical Science Review and Letters, 6(23), 1941-1949.

Dawidowicz, A. L., \& Typek, R. (2015). Thermal transformation of trans-5-O-caffeoylquinic acid (trans-5-CQA) in alcoholic solutions. Food Chemistry, 167, 52-60. https://doi.org/10.1016/j.foodchem.2014.06.086

Gürbüz, N., Uluişik, S., Frary, A., Frary, A., \& Doğanlar, S. (2018). Health benefits and bioactive compounds of eggplant. Food Chemistry, 268, 602-610. https://doi.org/10.1016/j.foodchem.2018.06.093

Jena, B. C., Srihari, B., \& Mahapatra, R. (2006). Pesticidal management practices to control brinjal shoot and fruit borer. Indian Journal of Entomology, 68(2), 193-196. 
Kan, S., Cheung, M. W., Zhou, Y., \& Ho, W. S. (2014). Effects of boiling on chlorogenic acid and the liver protective effects of its main products against $\mathrm{CCl}_{4}$-induced toxicity in vitro. Journal of Food Science, 79(2), 147-154. https://doi.org/10.1111/1750-3841.12350

Kashyap, V., Kumar, S. V., Collonnier, C., Fusari, F., Haicour, R., Rotino, G. L., Sihachakr, D., \& Rajam, M. V. (2003). Biotechnology of eggplant. Scientia Horticulturae, 97(1), 1-25. https://doi.org/10.1016/S0304-4238(02)00140-1

Maureal, A. M., Noriel, L. M., \& Esguerra, N. M. (1982). Life history and behavior of eggplant fruit borer. Annals-of-TropicalResearch, 4(3), 178-188.

Nasif, S. O., \& Siddiquee, S. (2020). Host preference. Mode of damage and succession of major insect pests of brinjal. Annual Research \& Review in Biology, 35(8), 68-78.

Naveed, M., Hejazi, V., Abbas, M., Kamboh, A. A., Khan, G. J., Shumzaid, M., Ahmad, F., Babazadeh, D., Fang, X. F., Modarresi-Ghazani, F., Hua, L. W., \& Hui, Z. X. (2018). Chlorogenic acid (CGA): A pharmacological review and call for further research. Biomedicine \& Pharmacotherapy, 97, 67-74. https://doi.org/10.1016/j.biopha.2017.10.064

Raina, J., \& Yadav, G. S. (2018). Brinjal shoot and fruit borer: Bio-ecology and management. Journal of Pharmacognosy and Phytochemistry, 7(4), 444-449.
Sharma, D. R. (2002). Bio-efficacy of certain insecticide and biopesticides against major pest of brinjal under field condition (M.Sc. (Ag.) Thesis). Indian Agriculture Research Institute, New Delhi, India.

Singhal, V. (2003). Indian agriculture. Indian Economic Data Research Centre, New Delhi.

Singla, P., Bhullar, M. B., \& Kaur, P. (2018). Biological studies on brinjal shoot and fruit borer, Leucinodes orbonalis Guenee. Journal of Entomology and Zoology Studies, 6(1), 161-165.

Stommel, J. R., \& Whitaker, B. D. (2003). Phenolic Acid content and composition of eggplant fruit in a Germplasm core subset. Journal of the American Society for Horticultural Science, 128(5), 704-710. https://doi.org/10.21273/JASHS.128.5.0704

Taher, D., Solberg, S. O., Prohens, J., Chou, Y., Rakha, M., \& Wu, T. (2017). World vegetable center eggplant collection: origin, composition, seed dissemination and utilization in breeding. Frontiers in Plant Science, 8, 1484. https://doi.org/10.3389/fpls.2017.01484

Vogt, T. (2010). Phenylpropanoid biosynthesis. Molecular Plant, 3(1), 2-20. https://doi.org/10.1093/mp/ssp106

Yann, L. (1972). The vegetable book. George Allen and Unwin Ltd. 